\title{
EFEITOS DA SALINIDADE EM ALGODOEIROS TRATADOS COM PRODUTOS QUÍMICOS*
}

\author{
PAULO R.C. CASTRO** \\ ANTONIO A. LUCCHESI** \\ RCGÉRIO T. FARIA*** \\ JOSÉ M.F.J. SILVEIRA*** \\ NELSON S. FONSECA JR.***
}

\section{RESUMO}

Estudaram-se os efeitos de polissulfeto de polietileno $(0,5 \%)$, oxietileno docosanol (5\%) e ácido succínico - 2,2-dimetil-hidrazida (2000 ppm), aplicados em pulverização, no desenvolvimento de algodoeiro cultivar 'IAC-RM3', submetido à adubação N-P-K (5:10:5) e à irrigação com solução de $\mathrm{NaCl}-\mathrm{CaCl}_{2}-\mathrm{MgCl}_{2}(1,00: 0,85: 0,15)$.

Os antitranspirantes permitiram aumento em área foliar do algodoeiro; sendo que o retardador de crescimento provocou redução na área foliar com relação ao controle, em condições de salinidade. Os produtos químicos promoveram maior aumento no peso seco em relação ao controle.

A taxa assimilatória líquida e a taxa de crescimento relativo mostraram-se mais altas nas plantas tratadas com produtos químicos em relação ao controle, nas condições de salinidade. Não ocorreram diferenças marcantes entre as plantas tratadas com antitranspirantes e o controle, com relação à razão de área foliar; sendo que este parâmetro mostrou-se inferior no tratamento com retardador de crescimento.

\section{INTRODUÇÃO}

Observações realizadas em três tipos de solos, levaram à conclusão de que o algodoeiro cresce normalmente quando o teor de cloreto de sódio no solo é da ordem de $0,5 \mathrm{~g}$ por quilograma de solo, com base em peso seco. Com teores mais elevados de cloreto de sódio as plantas apresentam subdesenvolvimento, diminuição no número de flores e maçãs menores que se abrem prematuramente; sendo que a colheita é reduzida e as fibras mostram-se muito curtas e finas. Quando a salinidade é muito alta, o crescimento e o florescimento são muito prejudicados (SIMONNEAU, 1946).

* Entregue para publicação em 22/12/1975.

* Departamento de Botânica E.S.A. "Luiz de Queiroz" - USP.

** Estagiários no Departamento de Botânica E.S.A. "Luiz de Queiroz" - USP. 
Verificou-se que o efeito de toxicidade de soluções monocatiônicas manifesta-se à concentrações mais baixas $(10 \mathrm{~g} / 1)$ do que a solução salina de água do mar. A irreversibilidade da perda de turgor das plantas de algodoeiro ocorreu com irrigação de solução concentrada a $30 \mathrm{~g} / \mathrm{l}$. A relativamente elevada tolerância das plantas deve-se ao efeito protetor dos catiônios contidos na solução do solo (MEL'NIKOVA et alii, 1972).

Realizou-se ensaio em que as plantas de algodoeiro desenvolveram-se sob diferentes níveis de salinidade no solo $(0,4 ; 0,7$ e $1,0 \%)$; sendo que em todos os tratamentos a razão entre os aniônicos cloreto e sulfato foi da ordem de 1:10. Observou-se que o crescimento da maioria das hastes foi reduzido, principalmente nos tratamentos com altos níveis de salinidade. $\mathrm{O}$ peso seco das folhas e hastes foi menor nos tratamentos com solução salina. Verificou-se também atraso no florescimento e na abertura das maçãs das plantas tratadas; sendo que a colheita foi reduzida em 50\% no tratamento com salinidade de 0,4\%, prejudicando ainda as propriedades das fibras (EL-SAIDI, 1973).

Durante o verão, observaram-se em regiões da África do Sul, Turquia e Egito, plantas de algodoeiro que se apresentavam cloróticas, com sistema radicular reduzido e conseqüente murchamento; sendo que estes sintomas foram atribuídos a uma anormal elevação da salinidade do solo. Esta alteração fisiológica que reduz o rendimento da cultura foi denominada de Topallik (GASSNER, 1943; BOUGHEY, 1944).

Reguladores de crescimento e outros produtos químicos têm sido utilizados com a finalidade de aumentar a tolerância dos vegetais aos altos niveis de salinidade. $O$ tratamento de sementes de trigo com cloreto de sódio, cloreto de (2-cloroetil) trimetilamônio, ácido giberélico e ácido bórico, causou aumento significativo na produção de grãos, sob irrigação com solução salina na concentração de 1000 ppm (BAKR AHMED et alii, 1970).

Verificou-se que o cloreto de (2-cloroetil) trimetilamônio aumentou a tolerância de trigo à salinidade obtida com a adição de cloreto de sódio, cloreto de cálcio e cloreto de magnésio na razão de 1,00: 0,85:0,15 (EL DAMATY et alii, 1964).

Aplicação do ácido succínico - 2,2-demetil-hidrazida (SADH) em soja aumentou a tolerância das plantas a niveis tóxicos de sais colocados em redor de suas raízes; sendo que o efeito do retardador de crescimento em plântulas de soja foi observado com a aplicação de fertilizante comercial 5-10-5 (N, $\mathrm{P}_{2} \mathrm{O}_{5}$ e $\left.\mathrm{K}_{2} \mathrm{O}\right)$, na superfície do solo, em quantidade que não causou dano nas plantas tratadas e provocou morte em plantas não tratadas (MARTH \& FRANK, 1961).

A salinização cloreto-sulfato possui um efeito definido no crescimento e desenvolvimento do algodoeiro. Enquanto relativamente baixos niveis de salinidade no solo $(0,3 \%)$ parecem estimular o crescimento das plantas, niveis elevados de salinidade $(0,8 \%)$ reduzem consideravelmente o crescimento e o desenvolvimento (STROGONOV, 1964).

Aplicações de produtos que diminuem a transpiração podem reduzir o déficit hídrico de plantas submetidas a condiçōes adversas (GALE \& HAGAN, 1966).

Aplicação de SADH em feijoeiro, aumentou a tolerância das plantas a níveis tóxicos de cloreto de sódio e sulfato de amônio (OTA, 1964). 
O objetivo deste trabalho foi verificar o efeito de antitranspirantes e de um retardador de crescimento no desenvolvimento de algodoeiro submetido a condições de salinidade.

\section{MATERIAIS E MÉTODOS}

Neste experimento utilizou-se o algodoeiro Gossypium hirsutum L. cv. 'IAC-RM3'. $\mathrm{O}$ ensaio desenvolveu-se em casa-de-vegetação, tendo-se efetuado a semeadura em 9/12/1974 diretamente em vasos de cerâmica, contendo solo com adubo químico N-P-K $(5: 10: 5)$.

Realizando-se os tratos culturais normais para a cultura, mantiveram-se três plantas por recipiente. Antes da aplicação dos produtos químicos, retirou-se uma planta de cada vaso.

Em 20/1/75 efetuaram-se os quatro tratamentos em cinco repetıções. Apiicou-se polissulfeto de polietileno (GOOD-RITE PEPS) 0,5\%, oxietileno docosanol (OEDGREEN) 5\%, ácido succínico - 2,2-dimetil-hidrazida (SADH) 2000 ppm, em pulverização; além do tratamento controle. Pulverizaram-se as folhas com soluções aquosas dos produtos, até mostrarem-se completamente molhadas.

Aplicou-se, sob a forma de irrigação, solução salina de cloreto de sódio, cloreto de cálcio e cloreto de magnésio na proporção de 1,00:0,85:0,15 em 25/1/75, em todos os tratamentos.

Em 31/1/75 coletou-se uma planta de cada recipiente para determinação da área foliar a través do conhecimento do peso seco de áreas conhecidas de amostras tomadas de 25 folhas. Obteve-se também o peso seco total da planta. Em 14/2/75 coletou-se a segunda planta e procedeu-se também à determinação da área foliar e do peso seco.

Para análise de crescimento do algodoeiro sob as condições de salinidade, calculou-se a taxa assimilatória líquida (TAL), a taxa de crescimento relativo (TCR) e a razão de área foliar (RAF), através das fórmulas respectivas (CASTRO, 1974)

\section{RESULTADOS E DISCUSSÃO}

No Quadro 1 temos os resultados referentes à variação em área foliar ( $\triangle \mathrm{AF})$ e variação em peso seco ( $\triangle \mathrm{PS}$ ) no período de 14 dias. Observamos também os valores referentes a taxa assimilatória líquida e a taxa de crescimento relativo, obtidos no intervalo de 14 dias; temos também a razão de área foliar obtida no 14 ọ dia. 
QUADRO 1 - Efeitos de produtos químicos na área foliar em $\mathrm{dm}^{2}$, no peso seco em $\mathrm{g}$, na TAL em $\mathrm{g} / \mathrm{dm}^{2} / \mathrm{dia}$, na TCR $\mathrm{em} \mathrm{g} / \mathrm{g} / \mathrm{dia}$ e na $\mathrm{RAF} \mathrm{em} \mathrm{dm}^{2} / \mathrm{g}$, de plantas de algodoeiro.

\begin{tabular}{lccccc}
\hline TRATAMENTOS & $\triangle \mathrm{AF}$ & $\triangle \mathrm{PS}$ & $\mathrm{TAL}$ & $\mathrm{TCR}$ & $\mathrm{RAF}$ \\
\hline CONTROLE & 3,5085 & 2,2196 & 0,0329 & 0,0107 & 0,4241 \\
GOOD-RITE PEPS & 4,0478 & 6,6958 & 0,0811 & 0,0293 & 0,4207 \\
OED-GREEN & 8,3112 & 6,2481 & 0,0671 & 0,0276 & 0,5735 \\
SADH & 2,0473 & 6,3816 & 0,1249 & 0,0284 & 0,2620
\end{tabular}

Verificou-se que os antitranspirantes promoveram um maior incremento em área foliar com relação ao controle, no período considerado; sendo que o retardador de crescimento provocou diminuição na área foliar do algodoeiro.

Notou-se que a variação em peso seco foi superior nos tratamentos com antitranspirantes e com retardador de crescimento, em relação ao controle. Isto parece demonstrar que a produtividade biológica é favorecida pela aplicação dos produtos químicos, em condições de salinidade.

Observou-se que, em condições de salinidade, a TAL mostrou-se mais elevada nos tratamentos com produtos químicos, sendo que o controle apresentou ganho em produtos de fotossíntese inferior àquele obtido em condições normais. ALVIM (1962) obteve $0,088 \mathrm{~g} / \mathrm{dm}^{2} /$ dia na TAL do algodoeiro em Lima, Peru; sendo que CASTRO et alii (1975a, 1975b) observaram TAL de 0,041 a $0,086 \mathrm{~g} / \mathrm{dm}^{2} /$ dia nas condições de Piracicaba.

A TCR mostrou-se mais elevada nos tratamentos químicos, em relação ao controle, sendo que a produção de matéria seca por unidade foliar foi mais prejudicada pela salinidade . no tratament (..controle. ALVIM (1962) verificou $0,056 \mathrm{~g} / \mathrm{g} / \mathrm{dia}$; sendo que CASTRO et alii (1975a, 1975b) observaram valores, na TCR, da ordem de 0,052 a 0,073 $\mathrm{g} / \mathrm{g} / \mathrm{dia}$, em algodoeiro.

A RAF mostrou-se inferior no tratamento com retardador de crescimento porque o produto promoveu redução na área foliar do algodoeiro. Não ocorreram diferenças marcantes entre os antitranspirantes e o controle, com relação à RAF. CASTRO et alii (1975a, 1975b), observaram valores da ordem de 1,346 a 1,673 $\mathrm{dm}^{2} / \mathrm{g}$ na RAF de algodoeiro cultivar 'IAC-RM3'; sendo portanto as RAF obtidas neste ensaio bastante inferiores, provavelmente devido ao ereito da salinidade provocada.

\section{CONCLUSÕES}

Os resultados deste ensaio, permitem as seguintes conclusões:

1 - O SADH promove redução na área foliar do algodoeiro; sendo que os antitranspirantes permitem aumento em área foliar com relação ao controle, em condições de salinidade.

2 - Antitranspirantes e SADH permitem maior aumento no peso seco do algodoeiro com relação ao controle, em condições de salinidade. 
3 - A taxa assimilatória líquida do algodoeiro tratado com SADH e antitranspirantes é superior à do controle, em condições de salinidade.

4 - Em algodoeiro tratado com $\mathrm{SADH}$ e antitranspirantes, a taxa de crescimento relativo é mais alta com relação ao controle, em condições de salinidade.

5 - Não há diferenças marcantes entre antitranspirantes e controle, com relação à razão de área foliar; sendo que a RAF é inferior no tratamento com SADH.

\section{SUMMARY}

\section{EFFECTS OF SALINITY ON COTTON PLANTS TREATED WITH CHEMICALS}

Studies were carried out to establish the effects of spray of polyethylene polysulfide $(5 \%)$, oxyethylene docosanol $(5 \%)$ and succinic acid-2,2-dimethylhydrazide $(2,000 \mathrm{ppm})$, in the growth of cotton 'IAC-RM3', under application of N-P-K $(5: 10: 5)$ and irrigation with solution of $\mathrm{NaCl}-\mathrm{CaCl}_{2}-\mathrm{MgCl}_{2}$ (1.00:0.85:0.15).

The antitranspirants promote increase in leaf area of cotton; and the growth retardant causes diminution in the leaf area in relation to check in salinity conditions. The chemicals promote increase in the dry weight in relation to check.

The net assimilation rate and the relative growth rate were superior in the plots that received the chemicals in relation to check in salinity conditions. It was not verified differences between the plants treated with antitranspirants and the check in relation to the leaf area ratio; that parameter was inferior in the treatment with the growth retardant.

\section{LITERATURA CITADA}

ALVIM, P.T., 1962. Los factores de la productividad agricola. Curso Internacional de Bases Fisiológicas de la Produción Agricola. IICA - OEA, Lima, Peru.

BAKR AHMED, M., HEGAZY, A.T., ASHOUR, N.I., EL-FOULY, M.M. \& MOURSY, H.A., 1970. Inducing salt tolerance in wheat. Beit. Trop. Subtrop. Landwirtsch Tropenveterinaermed, $8(3): 229-240$.

BOUGHEY, A.S., 1944. Physiological cotton wilt in the Sudan Gezira. Ann. Appl. Biol., 31(1): $12-1 \overline{8}$.

CASTRO, P.R.C., 1974. Análise de crescimento do amendoinzeiro (Arachis hypogaea L.) com relação à infestação de pragas. Anais da Esc.Sup. Agr. "Luiz de Queiroz", $31: 207-215$.

CASTRO, P.R.C., MENTEN, J.O.M., AGUILAR, J.A.E., MONTANHEIRO, M.N.S., PEREIRA, W.S.P. \& ROSATO, Y.B., 1975a. Efeitos de giberelinas no desenvolvimento do algodoeiro (Gossypium hirsutum L. cv. 'IAC-RM3'). Anais Esc. Sup. Agr. "Luiz de Queiroz", 32 (no preio).

CASTRO, P.R.C., IUKI, V.A., SOUSA, M., VENTORIM, N., KUNIYUKI, H. \& ROLIM, F.A., 1975b. Efeitos do CCC no desenvolvimento do algodoeiro (Gossypium hirsutum L. cv. 'IAC-RM3'). Anais Esc. Sup. Agr. "Luiz de Queiroz", 32 (no prelo). 
EL DAMATY, H., KUHN, H. \& LINSER, H., 1964. A preliminary investigation on increasing salt tolerance of plants by application of (2-chloroethyl) - trimethyl ammonium chloride. Agrochimic ${ }^{n}$ 8:131-138.

EL-SAIDI, M.1., 1973. Effect of different salinity levels on growth, development and some physiological processes of cotton plants: I. Effect of adding salts before sowing. Z. Acker Pflanzenbau, 138(4):331-340.

GALE, J. \& HAGAN, R.M., 1966. Plant antitranspirants. Ann. Rev. Plant Physiol., 17:269-282.

GASSNER, G., 1943. Die Topallik - Erkrankung der Baumwolle. Phytopath. Zeitschr, 14(5): 518-521.

MARTH, P.C. \& FRANK, J.R., 1961. Increasing tolerance of soybean plants to some soluble salts through application of plant growth - retardant chemicals. Agr. Food Chem., 9:359-361.

MEL'NIKOVA, M.K., TAGAEV, S.R. \& ZUBAREVA, I.F., 1972. Uptake of sodium, calcium, and chlorine by cotton plants during irrigation with a solution similar to sea water. Fiziol. Rast., 19(2):396-401.

OTA, T., 1964. Increasing tolerance of kidney bean plants (Phaseolus vulgaris) to toxic levels of sodium chloride and ammonium sulfate through application of B 995 (plant growth retardant). Plant Cell Physiol., 5(2):255-258.

SIMONNEAU, P., 1946. Observations sur la resistance au sel du cotonnier. Fruits et Primeurs Afrique du Nord, 166:43-46.

STROGONOV, B.P., 1964. Physiological basis of salt tolerance of plants. Israel Program for Scientific Translations, Jerusalem, 279 p. 